\title{
Genetic structure of the vairone Telestes souffia in the eastern part of Lake Constance, central Europe
}

\author{
F. M. Muenzel*†, W. Salzburger*†, M. Sanetra*, B. Grabherr \\ AND A. MEYER* ${ }^{*}$ \\ *Lehrstuhl für Zoologie und Evolutionsbiologie, Department of Biology, University of \\ Konstanz, Universitätsstraße 10, 78457 Konstanz, Germany, †Zoological Institute, University \\ of Basel, Vesalgasse 1, 4051 Basel, Switzerland and $\ddagger$ Department of Biology, University of \\ Salzburg, Hellbrunnerstrasse 34, 5020 Salzburg, Austria
}

\begin{abstract}
Examination of the genetic structure of the vairone Telestes souffia based on 10 nuclear markers (microsatellites) revealed little-to-moderate genetic differentiation between geographically adjacent populations in the eastern part of Lake Constance in central Europe. Results emphasize the critically endangered status of this freshwater fish in the upper Rhine River system.
\end{abstract}

Key words: bottleneck; conservation; Cyprinidae; freshwater fish; microsatellites; population genetics.

Climatic oscillations during the Quaternary had an important effect on the actual distribution and the genetic structure of many freshwater fish species, especially in previously glaciated areas due to founder events (Bernatchez, 2001; Ramstad et al., 2004). In addition to natural events, human interactions (such as fisheries, habitat fragmentation and pollution) have imprinted the population genetic structure of many fish species in the recent past (Laroche \& Durand, 2004). Combining population genetic data with geographical information, life-history traits of a species and data on past events such as climatic fluctuations or human interference can provide important insights into the factors that shaped the structure of populations, the evolutionary history of a species and its conservation status.

The vairone Telestes souffia (Risso) [Fig. 1(a)] is a primary freshwater fish distributed in the Alps and the surrounding regions. It inhabits the upper reaches of the main central European river systems such as the Rhine, Rhône, Danube and Po. Previous research on the phylogeography of this cyprinid in central Europe revealed that two main genetic lineages exist, which are likely to have colonized the Alps after the last glaciation cycle either from the south (Italian clade) or from the east (Alpine clade) (Salzburger et al., 2003; Marchetto et al., 2010). These two

§Author to whom correspondence should be addressed. Tel.: +497531884163 ; fax: +497531883018 ; email: axel.meyer@uni-konstanz.de 

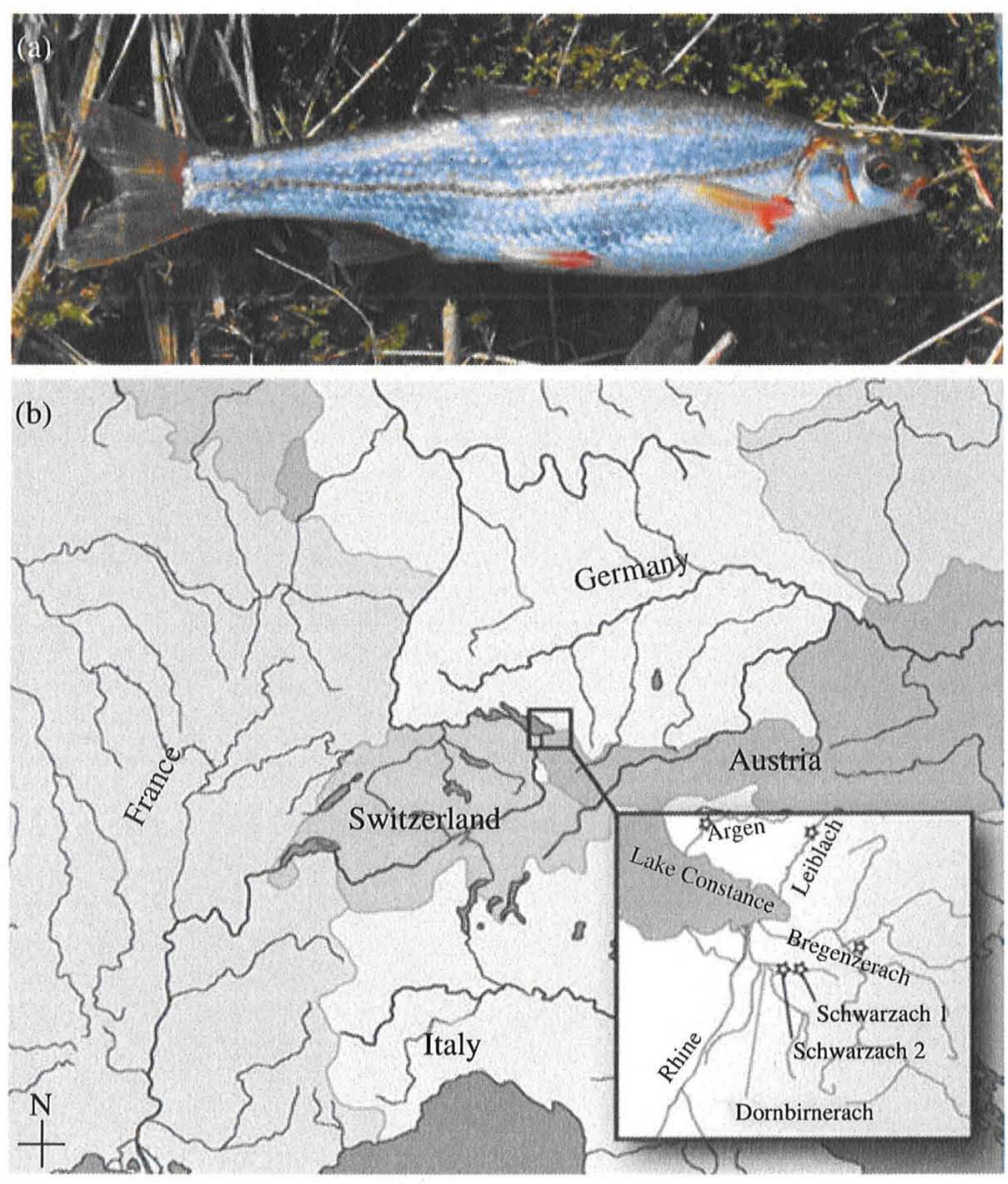

FIG. 1. (a) Telestes souffia and (b) rivers studied in the eastern part of Lake Constance in Central Europe.

genetic lineages are congruent with the sub-species T. s. muticellus in Italy and T. s. souffia or T. s. agassizi in the drainages of Danube, Rhine and Rhône. According to mitochondrial DNA data by Salzburger et al. (2003), the Rhine system T. souffia represents the youngest assemblage with a comparatively low number of mitochondrial haplotypes, directly derived from Danubian ancestors. These results suggest low dispersal ability of $T$. souffia and a limited genetic diversity in the Rhine River system.

Because of its little economic importance, major faunal translocations of $T$. souffia in Europe are not known. The only known exception is a discontinued restocking programme in the Jossa River (a tributary of the Main River in Germany), where fish from the Birs River in Switzerland have been released (R. Bless, pers. comm.). Therefore, at least in the Alpine area, the present distribution of $T$. souffia is expected to reflect the natural population history. This makes $T$. souffia an interesting model species to study the effects of paleoclimatic and geological events as well as human influence on the present distribution of central European freshwater fishes. 
Telestes souffia is a rather specialized cyprinid species known for its intolerance to low oxygen levels and dependency on gravel substratum for spawning (Bless, 1996). As a threatened species, it is listed in Appendix III of the Bern Convention on the Conservation of European Wildlife and Natural Habitats, Appendix II of the E.U. Directive on the Conservation of Natural Habitats and Wild Fauna and Flora and is categorized as rare by the International Union for the Conservation of Nature (IUCN). Investigating the conservation status of $T$. souffia in France, Salducci et al. (2004) found that one quarter of the populations studied had experienced a recent population decline (bottleneck) and that four of the 19 populations are of a critically endangered status indicated by low genetic polymorphisms and weak population densities.

In this study, nuclear markers (microsatellites) were used to investigate the population genetic structure of $T$. souffia from the upper Rhine drainage system in the eastern part of Lake Constance in central Europe. Of particular interest was the question: whether a lake could act as migration barrier for a riverine freshwater fish. Both the basin of Lake Constance and the surrounding landscape were shaped during the last glacial maximum (Wuerm, $<15000$ years before present), therefore colonization of this area by freshwater fish could only occurred have after this event. Hence, this study focused on the influence of relatively recent events on the dynamics and structure of populations of a specialized freshwater fish.

The study area comprised four rivers of the Rhine system in the eastern part of Lake Constance: Argen, Leiblach, Bregenzerach and Schwarzach [Fig. 1(b)]. Three (Leiblach, Argen and Bregenzerach) of the four rivers under study flow directly into Lake Constance, whereas the Schwarzach River in Austria flows into the River Dornbirner Ach, which is connected to Lake Constance. This results in a rather small geographic area with shoreline distances between the respective river mouths from c. 2 to $25 \mathrm{~km}$. About 20 individuals were sampled from one population per tributary (Table I); two populations were sampled within the Schwarzach River (Schwarzach 1 and $2 ; n=17$ and $n=51$, respectively), which are separated by $c .2 \mathrm{~km}$ including a stretch where the riverbed has been canalized. Individuals were caught by electrofishing; they were weighed, measured (standard and total length) and photographed, and a fin-clip preserved in $100 \%$ ethanol was taken for DNA analysis. Total genomic DNA was extracted using a sodium chloride extraction protocol (Bruford et al., 1998). Ten nuclear microsatellite loci, designed for T. souffia (Lsou05, Lsou08, Lsou09, Lsou11, Lsou14, Lsou19, Lsou21, Lsou27, Lsou29 and Lsou34), were genotyped as described by Muenzel et al. (2007). Basic genetic descriptive statistics: number

TABLE I. Population (see Fig. 1) parameters from Telestes souffia

\begin{tabular}{lccccccc}
\hline Population & $n$ & $F_{\mathrm{IS}}$ & $N_{\mathrm{a}}$ & $N_{\mathrm{e}}$ & $H_{\mathrm{E}}$ & $H_{\mathrm{O}}$ & $N_{\mathrm{DL}}$ \\
\hline Schwarzach 1 & 51 & 0.075 & 7.8 & 4.04 & 0.68 & 0.67 & 1 \\
Schwarzach 2 & 17 & 0.093 & 6.1 & 3.86 & 0.73 & 0.72 & 0 \\
Leiblach & 20 & 0.054 & 5.9 & 3.48 & 0.65 & 0.62 & 3 \\
Argen & 21 & 0 & 6.5 & 3.59 & 0.68 & 0.72 & 0 \\
Bregenzerach & 21 & 0.107 & 6.4 & 3.45 & 0.66 & 0.63 & 5
\end{tabular}

$n$, number of individuals; $N_{\mathrm{a}}$, mean number of alleles; $N_{\mathrm{e}}$, effective number of alleles; $H_{\mathrm{E}}$, expected heterozygosity; $H_{\mathrm{O}}$, observed heterozygosity; $N_{\mathrm{DL}}$, number of deviations from linkage disequilibrium $(P>0.05)$. 
of alleles, expected $\left(H_{\mathrm{E}}\right)$ and observed heterozygosities $\left(H_{\mathrm{O}}\right)$ and deviations from the Hardy-Weinberg equilibrium (HWE) (per population across all loci and per locus across all populations using Fisher's exact test) were compiled using GENEPOP (Raymond \& Rousset, 1995). The effective number of alleles $\left(N_{\mathrm{e}}\right)$ was calculated as the reciprocal of $\Sigma p_{i}{ }^{2}$ (Hartl \& Clark, 1997). Linkage disequilibrium was tested for all possible pairs of loci in each population and globally for each pair of loci across populations with GENEPOP. The extent to which the riverine populations of $T$. souffia are isolated from one another was investigated by calculating Wright's $F$-statistics (Weir \& Cockerham, 1984) as implemented in GENEPOP. In addition, a Bayesian model-based clustering algorithm implemented in the computer programme STRUCTURE 2.0 (Pritchard et al., 2000) was applied. Analyses were performed using the admixture and the non-admixture models and assuming correlated and independent allele frequencies with a burn-in period of 50000 iterations, followed by 200000 Markov chain Monte-Carlo (MCMC) repetitions, an inferred $K$ from one to 10 and three iterations each. Testing for recent bottlenecks in populations was conducted with the test statistics M-Ratio (Garza \& Williamson, 2001). Settings applied were $N_{\mathrm{e}}=1000$ (and $N_{\mathrm{e}}=10000$ ), $\mu=0.01$ and $\mu=0.001$ (corresponding to the generally assumed microsatellite mutation rates in fishes; Jones et al., 1999; Shimoda et al., 1999), $p_{\mathrm{s}}=0.8$ and $\Delta_{\mathrm{g}}=3.5$ (Garza \& Williamson, 2001). Statistical significance was estimated by simulating an equilibrium distribution of $M$ using 1000 replicates, according to the method described in Garza \& Williamson (2001) and ranking the calculated value relative to the equilibrium distribution. Using conventional criteria, there is evidence of significant reduction in population size if $<5 \%$ of the replicates are below the observed value.

The mean expected and observed heterozygosities $\left(H_{\mathrm{E}}\right.$ and $\left.H_{\mathrm{O}}\right)$, the mean number of alleles and the effective number of alleles are given in Table I. The total number of alleles per locus ranged from two to 16 with an average of nine alleles per locus when all populations were combined. Considering the populations separately, the mean number of alleles ranged from 5.9 (Leiblach) to 7.8 (Schwarzach 1). Analysis of the effective number of alleles $\left(N_{\mathrm{e}}\right)$ shows a smaller range between populations: $3 \cdot 5 \leq N_{\mathrm{e}} \leq 4 \cdot 0$. In population Schwarzach 1 , the highest number of alleles (7.8) was observed, while the effective number of alleles was only 4.0 resulting from many low-frequency alleles. Thus, the mean effective number of alleles is similar between all five populations investigated. Exact tests for linkage disequilibrium across all five populations revealed significant linkage at the $1 \%$ level between loci Lsou05 and Lsou19, between Lsou11 and Lsou14 and between Lsou8 and Lsou14. Deviations from HWE (heterozygote deficil; $P<0.01$ ) were detected for Lsou 9 (Bregenzerach), Lsou14 (Schwarzach 1), Lsou19 (Argen) and Lsou34 (all populations but Leiblach); locus $L$ sou 34 was consequently excluded from further analyses. All but one pair-wise comparison among the five river populations connected via Lake Constance resulted in significant $F_{\mathrm{ST}}$ values (Table II). The fixation indices indicated little genetic differentiation between the investigated populations. As expected, the populations Schwarzach 1 and Schwarzach 2, which are separated by c. $2 \mathrm{~km}$ only, do not show significant levels of genetic differentiation. The population assignment test with the software STRUCTURE based on 10 microsatellite loci did not resolve a distinct population structure within a total of 130 individuals. Calculating the $M$-ratio (Garza \& Williamson, 2001) revealed strong evidence for past demographic reduction in the population size for all five populations under study: Schwarzach 1 ( $M=0.56$, 
TABLE II. Fixation indices for pair-wise comparisons between populations (see Fig. 1) of Telestes souffia

\begin{tabular}{lcccc}
\hline & Schwarzach 1 & Schwarzach 2 & Leiblach & Argen \\
\hline Schwarzach 1 & & & & \\
Schwarzach 2 & $0.013^{\mathrm{NS}}$ & & & \\
Leiblach & $0.034^{* * *}$ & $0.043^{* * *}$ & & \\
Argen & $0.016^{* * *}$ & $0.027^{* * *}$ & $0.022^{* * *}$ & \\
Bregenzerach & $0.042^{* * *}$ & $0.048^{* * *}$ & $0.027^{* * * *}$ & $0.029 * * *$ \\
\hline
\end{tabular}

$* * * P<0.001 ; \mathrm{NS}$, non-significant.

$P \leq 0.00)$, Schwarzach $2(M=0.52, P<0.01)$, Leiblach $(M=0.53, P<0.01)$, Argen $(M=0.55, P \leq 0.001)$ and Bregenzerach $(M=0.50, P<0.01)$. This was true for both the assumed effective population sizes $\left(N_{\mathrm{e}}=1000\right.$ and 10000$)$ and the applied mutation rates $(\mu=0.01$ and 0.001$)$.

While the phylogeographic history of $T$. souffia in the main central European river systems has been studied in some detail (Gilles et al., 1998; Salzburger et al., 2003), little is known about its fine-scale genetic structure in different parts of central Europe. Salducci et al. (2004) characterized T. souffia's genetic structure demonstrating its critical conservation status in France (Rhône basin). The present sampling sites in the upper Rhine system represent an even smaller geographic scale with only between two and $25 \mathrm{~km}$ lakeside distance between river mouths. The pair-wise $F_{\mathrm{ST}}$ comparisons revealed a little-to-moderate, yet significant, degree of genetic differentiation between the populations (Table II). This finding could suggest that the lacustrine environment of Lake Constance acts as a barrier to gene flow for the riverine specialist $T$. souffia (note that $T$. souffia has never been found within the lake itself).

A mark-recapture study in the $T$. souffia population from the River Argen uncovered a seasonal migration behaviour between a common winter habitat in the form of a deeper pool in a tributary and the spawning (spring) and foraging (summer) grounds in the riverbed itself (Wocher \& Rösch, 2005). Only first-year juveniles did not follow this migration and stayed in the river throughout their first year. Similar observations have been made in the Schwarzach, where $T$. souffia are known to remain in winter in relatively high densities (up to 400 individuals per $100 \mathrm{~m}$ stream course) in an anabranch, while in the main stream the highest densities are found in spring and summer (up to 100 individuals per $100 \mathrm{~m}$ stream course) (B. Grabherr, unpubl. obs.). Thus, while seasonal migrations on a small geographic scale and within the same habitat type (gravel) are well documented in $T$. souffia, migrations over larger geographic distances and across different habitat types (i.e. lake habitat) appear to be rather rare. This can be attributed to the fish's stenotopic behaviour and to habitat disturbances as they occur throughout the species distribution range.

All populations investigated here show signatures of population bottlenecks adding genetic support to the declaration of $T$. souffia as a critically endangered species. In all four rivers studied, $T$. souffia is rare and only known from some localities, which typically represent the most undisturbed and the most structured sites, such as anabranches (B. Grabherr, unpubl. obs.). Yet, the long-term observation of population densities in the Schwarzach revealed that annual variation in population density 
is high and that single events such as high temperatures or floods can have severe effects on populations. The high temperatures and low water stands in summer 2003, for example, led to a population decline to $c .25 \%$ in the mainstream and $80 \%$ in the Anabranch; a flood in the summer of 2005 reduced the juvenile population dramatically (B. Grabherr, unpubl. obs.). A sympatric population of chub Leuciscus cephalus (L.), a more widespread and a more generalist species, was only marginally affected by these events. It is such climatic events and the reduction of natural habitats caused by human impact that are probable causes for population bottlenecks and declines in $T$. souffia. To which extent the reduction of genetic diversity leads to reduced adaptability in $T$. souffia would need to be studied further.

Our thanks go to A. Lunardon for organizing the electrofishing campaigns, for providing additional samples and for discussions, to the Assistant Editor and two anonymous reviewers for valuable comments, as well as to E. Dossow from the Fischbrutanstalt Langenargen who kindly provided samples from the River Argen. Financial support was provided by grants of the Deutsche Forschungsgemeinschaft (SFB454, Bodenseelitoral) and the University of Konstanz to A.M., and the Center for Junior Research Fellows of the University of Konstanz to W.S.

\section{References}

Bernatchez, L. (2001). The evolutionary history of brown trout (Salmo trutta L.) inferred from phylogeographic, nested clade, and mismatch analyses of mitochondrial DNA variation. Evolution 55, 351-379.

Bless, R. (1996). On the spawning behaviour and the ecology of early life stages of the soufie (Leuciscus souffia RISSO, 1826). Fischökologie 10, 1-10.

Bruford, M. W., Hanotte, O., Brookfield, J. F. Y. \& Burke, T. (1998). Multi-locus and singlelocus DNA fingerprinting. Molecular Genetic Analysis of Populations (Hoelzel, A. R., ed.), pp. 283-336. New York, NY: Oxford University Press.

Garza, J. C. \& Williamson, E. G. (2001). Detection of reduction in population size using data from microsatellite loci. Molecular Ecology 10, 305-318.

Gilles, A., Chappaz, R., Cavalli, L., Lörtscher, M. \& Faure, E. (1998). Genetic differentiation and introgression between putative subspecies of Leuciscus souffia (Teleostei: Cyprinidae) of the region of the Mediterranean Alps. Canadian Journal of Fisheries and Aquatic Sciences 55, 2341-2354.

Hartl, D. L. \& Clark, A. G. (1997). Principles of Population Genetics. Sunderland, MA: Sinauer Associates.

Jones, A. G., Rosenqvist, G., Berglund, A. \& Avise, J. C. (1999). Clustered microsatellite mutations in the pipefish Syngnathus typhle. Genetics 152, 1057-1063.

Laroche, J. \& Durand, J. D. (2004). Genetic structure of fragmented populations of a threatened endemic percid of the Rhone river: Zingel asper. Heredity 92, 329-334.

Marchetto, F., Zaccara, S., Muenzel, F. M. \& Salzburger, W. (2010). Phylogeography of the Italien vairone (Telestes muticellus, Bonaparte 1837) inferred by microsatellite markers: evolutionary history of a freshwater species with a restricted and fragmented distribution. BMC Evolutionary Biology 10, 1111.

Muenzel, F. M., Sanetra, M., Salzburger, W. \& Meyer, A. (2007). Microsatellites from the vairone Leuciscus souffia (Pisces: Cyprinidae) and their application to closely related species. Molecular Ecology Notes 7, 1048-1050.

Pritchard, J. K., Stephens, M. \& Donnelly, P. (2000). Inference of population structure using multilocus genotype data. Genetics 155, 945-959.

Ramstad, K. M., Woody, C. A., Sage, G. K. \& Allendorf, F. W. (2004). Founding events influence genetic population structure of sockeye salmon (Oncorhynchus nerka) in Lake Clark, Alaska. Molecular Ecology 13, 277-290.

Raymond, M. \& Rousset, F. (1995). GENEPOP (version 1.2): a population genetics software for exact tests and ecumenicism. Journal of Heredity 86, 248-249. 
Salducci, M. D., Martin, J.-F., Pech, N., Chappaz, R., Costedoat, C. \& Gilles, A. (2004). Deciphering the evolutionary biology of freshwater fish using multiple approachesinsights for the biological conservation of the vairone (Leuciscus souffia souffia). Conservation Genetics 5, 63-77.

Salzburger, W., Brandstätter, A., Gilles, A., Parson, W., Hempel, M., Sturmbauer, C. \& Meyer, A. (2003). Phylogeography of the vairone (Leuciscus souffia, Risso 1826) in Central Europe. Molecular Ecology 12, 2371-2386.

Shimoda, N., Knapik, E. W., Ziniti, J., Sim, C., Yamada, E., Kaplan, S., Jackson, D., de Sauvage, F., Jacob, H. \& Fishman, M. C. (1999). Zebrafish genetic map with 2000 microsatellite markers. Genomics 58, 219-232.

Weir, B. S. \& Cockerham, C. C. (1984). Estimating F-statistics for the analysis of population structure. Evolution 38, 1358-1370.

Wocher, H. \& Rösch, R. (2005). Migrations of soufie (Leuciscus souffia agassizii, Val. 1844) in a natural river and a tributary determined by mark-recapture. Archiv für Hydrobiologie 165, 77-87. 